\title{
Feminist Utopia: A New Viewpoint of Interpreting British and American Literature
}

\author{
Shaobin Zhou \\ School of Foreign Languages, Xichang College, Xichang, 615013, China
}

Keywords: feminism; utopia; British and American literature;

\begin{abstract}
The literary history of feminist utopian novels has always not been concerned by the literature circles and even excluded from the research field of serious feminist literature. By the latter half of the 18th century, the feminist utopian novels was listed as an important literary phenomenon and recognized as a unique entry point of integrating the British and American literature. From the perspective of feminist utopia, this paper elaborates the definition of utopia and feminist utopia, discusses the development and evolution of feminist utopian works and their influences on feminist utopian literature, points out the criticism and dissatisfaction with male-dominated culture in feminist utopian novels. Through the review and introspection of the living status of the female, the female humanistic care and ecological care are integrated as two new viewpoints of the research on feminist utopian works, so as to comprehensively know the development footprint of feminist utopian literature.
\end{abstract}

\section{Overview of feminist utopia}

(I) Utopia and feminist utopia

The word "feminist utopia" first occurred in the 1980s. The feminist utopian novels refers to those revealing the feminist thoughts, reflecting the spirit of utopia and concerning the female and human future, with novel as the carrier. The feminist utopian works are called as utopian novel genre. The spirit of utopia is the soul for feminist writing and based on the reality and beyond the reality, which continuously pursues the pioneering spirit of ideal and represents the deepest desire of the female in each era. Its basis is the criticism and negation of bisexual order and also the affirmation and pursuit of ideal bisexual relations mode. The feminist utopian novels provide literature means for the theoretical exploration of feminists, which is the experiment that verifies the assumptions of feminist utopia and also the best carrier of feminist thought and spirit of utopia. The problems concerned by feminist and utopianism are discussed in the form of novel. Thus, it can be seen from the above that the feminist utopian novels criticize the patriarchal oppression and design the female and human future.

(II) Development and evolution of feminist utopian literatures

The feminist utopian literature emerged in the latter half of the 18th century and vigorously developed into utopian novel genre in the 1820s. From the history of western culture, the feminist utopian thoughts have been of long standing in the literature field. In conclusion, the statement of early feminist utopian thoughts has been scattered, with limited scale.

According to the relevant literature, the feminist utopian literature was first occurred in Plato's Timaeus and elaborated in Plato's Utopia. Utopia was also mentioned in Plutarch's Lycurgue about the ideal description of Sparta. Besides, the legend of Atlantis inspired many utopian mythologies and the outline and recalling of "Golden Age" in Hesiod's Theogony: Works and Days also belonged to early utopian works. The early representative classical works included Sarah Robinson Scott's Temple of Thousand Years published in 1976, Charlotte Perkins Gilman's Herland in the late 19th century and early 20th century, Maggie Piercy's Woman on the Edge of Time and Monique Vertigo's Guerrilla Girl in the 1960s.

Thomas More redefined the traditional concept of Utopia and integrated the self criticism, thus providing a new imagination space for the outlook on the social reform. The feminist utopian literature was creatively used as a narrative style by Thomas More, who conducted writing practice in the identity of a politician, so his work, Utopia, became a unique genre in Western literature 
history, laid a foundation for the normal form of modern utopian novels and had an important realistic significance in the development history of western utopian literature.

\section{Influence of feminist utopia on literature}

Some American scholars point out: "The reconstruction of human culture advocated by feminist utopia is the objective of feminist writing." There is a common and consistent objective between feminist thoughts and utopian thoughts, that is, reconstruction of human culture. Therefore, the common objective of literary creation by using the utopian thoughts or feminist thoughts is to integrate the reconstruction of human culture and resistance and subversion of the patriarchal society.

The traditional feminist utopian literature never achieved the bisexual equality in a real sense in the history, which only simply showed the longing for future beautiful society or surficially reflects the various dissatisfaction with the social reality. However, the modern feminist utopian works strive to build a society with bisexual equality and without any gender oppression and discrimination and concern the female and human future, so as to reveal the spirit of utopia and really reflect the feminist thoughts.

\section{Rebuild the female ego and resist and subvert the patriarchal culture}

The patriarchal culture has dominated the whole society over the time, in which it is thought that only the male is the leading force and the representative of human, and the female is only the property of the male or goods for exchange and even the fertility machine and sex object, so the female, which is always controlled and exploited, lives a hollow and helpless life, without any dignity. Thus, the voice of rebuilding the female ego and resisting and subverting the patriarchal culture increasingly rises, to which the emerging of massive feminist utopian literature is the most powerful weapon. Among various feminist utopian works, there is only a main line, that is, subversion of patriarchal culture and rebuilding of female ego distorted and suppressed by such culture.

In the late 19th century and early 20th century when it was the golden age of feminist utopia, Charlotte Perkins Gilman's Herland was a powerful evidence and also the refraction of feminist concept, in which she throughly subverted the patriarchal discourse in the reality and interpreted the feminist discourse and cultural brilliance incisively and vividly by virtue of the imagination and creation of the human's spiritual home in the form of utopian novel. Herland is an unprecedented work in the history of feminist utopian literature and Gilman is also an unprecedented classical pivotal figure in the feminist utopian novels.

British Novelist Mrs. Gaskell's Cranford Town, who was half a century earlier than Gilman, continuously builds a feminist kingdom far away from patriarchy, in which the society is like a pure land and the dominated value system is not affected by any values brought by industrialization. The feminist world described in the novel completely gets rid of various limitations and chains of patriarchal culture and each group has a close relationship, thus forming a feminist independent area, that is, feminist utopia.

According to the analysis of the representative of feminist utopian works, Charlotte Perkins Gilman's Herland and Mrs. Gaskell's Cranford Town, Gilman presents a recognized "woman” which can be regarded as the female spirit and body home, thus successfully accomplishing the pursuit of female genealogy. The female culture is brilliant due to the absence of patriarchal discourse and culture. At the end, the three girls of kingdoms of females get married with three American men, expecting to produce higher civilization. However, Mrs. Gaskell's Cranford Town builds an community comprising the female, which only rejects the male values, rather than the male. This symbolizes that the classical feminist utopian novels have preliminarily got out of narrow sense of radical feminists and also builds the female narrator. The interlacing of personal narrative voice and collective narrative voices can contemporarily put them in the community and 
provide the legal basis. The two works gather people "scattered among the male" to create the conditions of "we", so as to form the "collective narrative voice" at different levels.

In conclusion, the feminist utopian works are not only the female liberation, but also the sound development of human, which think the construction of feminist culture and feminist discourse and the deconstruction of patriarchal culture are interlaced and the creation of bisexual utopia is optimistic when the general consciousness of 'human' contains both the male and the female, rather than only the male. The rebuilding of female ego and resistance and subversion of patriarchal culture are the main line running thought such works.

\section{Two new viewpoints in the research on feminist utopian literature}

(I) Review and retrospection of the living status of the female

The living status of the female is the realistic life foundation of feminist utopian novels, in other words, the social imbalance caused by the increasingly tight bisexual relations and the survival predicament in the man-centered society have always been the core problems concerned by the feminist utopian literature.

For example, in The Handmaid's Tale, a utopian novel, the author has presented the oppression of the female in the patriarchal society and metaphorizes the future of the human by constructing the survival predicament of the female. However, it also integrates the memory of the life in the 1980s, showing the thoughts on the living status of both sexes, especially the female. With the findings of several historians as the clue, the author tells a story concerning a woman who is a handmaid in Gilead and narrowly escapes through a tape, which is the personal experience of the leading character in the early 21st century. The future world described in the novel is chilling.

It is clear that The Handmaid's Tale associates the real survival problems of the female with the fate and destiny of human society, exaggerates the worry and potential hazard in the bisexual relations in the realistic society, and shows the survival predicament of bisexual relations, metaphorizing the reality. In a certain sense, the influence of this work is far beyond the scope of pure literature and is of far-reaching realistic research significance.

(II) Ecological care in the feminist utopian works

It is known that the essential way to solving the ecological crisis is to realize the harmony and balance of science and ecology as well as human and nature. With the increasingly development and emerging of ecological feminist thoughts, the feminist utopian literature mainly discusses the problem about how to balance the economic development and ecological environment and how to realize the harmony of human and nature. Since the 20th century, the feminist utopian literature has paid great attention to the social crisis and environmental crisis that confuse the human society and discussed how to realize the harmony between science and ecology as well as human and nature by various means, taken mutual benefits and love as the core values and combined the female liberation and ecological problems.

For example, in Herland, women highlight the harmony between human and nature and advocate the coexistence of human and nature. They also think that the human is an indispensable part of nature and all life forms in the nature should be equal and love and cooperate with each other. The human should respect everything in the nature and make the nature become a more clean and effective residence by technical means.

In The Left Hand of Darkness, the scientific and technological development is slow and the high technology of Cold Star is mainly used to resist the cold and bad natural environment. Besides, the scientific and technological development of human has certain limitation and precondition and the scientific and technological application is to protect the normal operation of ecosystem. For example, the scientifical and technological results which take three years on the earth can be accomplished for about 30 years on Cold Star.

In The Handmaid's Tale, the author never claims to restrain the scientific and technological development. The feminist utopian novels highlight the technological development under the guidance of morality and ethics and keeps the balance of survival and development, science and humanity and human and nature. 


\section{Conclusion}

The increasingly serious ecological crisis, population crisis, gender discrimination and a series of other problems always restrain the development of human society. Under this severe social background, many feminist utopian litterateurs pursue and look forward to the ideal society due to their dissatisfaction with the realistic life, show the female's deepest desire and pursuit and affirmation of ideal bisexual relation mode, strive to open a writing path different from the realism, replace the traditional backward social mechanism by the social structure characterized by the social sharing and natural harmony, and express their longing for the female future and imagination of the beautiful human society in the future in the form of utopian works, so as to promote people to review and retrospect the realistic social environment that they live.

\section{References}

[1] Liu Ying. Humanistic and Ecological Concern in American Feminist Utopian Novels[J]. Foreign Languages and Their Teaching , 2006

[2] Cui Yu'e. Construction and Deconstruction — Research on Feminist Utopian Novels in British and American Literatures[D]. Lanzhou University, 2008

[3] Ou Xiangying. Research on Western Contemporary Feminist Utopian Novels[D]. Sichuan University, 2007

[4] Zeng Gui'e. Dialogue of Ideal and Reality-On Normal Form of Feminist Utopian Novels[J]. Foreign Literatures, 2012.

[5] Liu Ying. Criticism and Prospect: Historical Mission of British and American Feminist Utopian Novels[J]. Journal of SISU, 2006. 